\title{
EL CUERPO ALBERGADO \\ DEL CAOS AL HABLA DE LOS ÁRBOLES
}

\author{
Sara Reyes Vera \\ sarareyes.rpf.ull@gmail.com
}

\section{RESUMEN}

El caos, considerado como principio generador desde Hesíodo, es el origen en el que pensamos la existencia del cuerpo como lugar de la sabiduría pero también de la vulnerabilidad. En el lenguaje encuentra albergue a esa fragilidad, y su lugar en los libros dibuja la manera de expresar sabiduría como inteligibilidad que se proyecta sobre dicho caos. Los libros hablan por los árboles y la Tierra por estos, en esa metáfora la idea de cuidado del cuerpo es también el cuidado del planeta. La especie humana en contrato con la naturaleza debe protegerla a favor de su propia perpetuación. La casa que alberga la vida es pensada desde la filosofía en este ensayo unida a la ciencia y la poesía.

Palabras Clave: caos, cuerpo, deseo, verdad, cautela, habla, libros, naturaleza.

\section{ON THE SPEECH OF TREES AND}

THE SHELTERED BODY

\section{Abstract}

Chaos, considered a generating principle since Hesiod, is the basis in which we think the existence of the body as a locus of wisdom - but also vulnerability. Language represents a shelter for this fragility, and its place in books molds the way to express wisdom as intelligibility which projects itself into said chaos. Books speak for trees and Earth for them, in this metaphor the idea of caring for the body is the same as caring for Earth. Human species in contract with nature must protect it, for its own perpetuation. The house that shelters life is expressed philosophically in this essay joined to science and poetry

KeYwORDs: chaos, body, desire, truth, caution, speech, books, nature. 
Hesíodo describe que el origen fue una "profundidad abierta»" el abismo que se abre al vacío. "En primer lugar existió, realmente, el caos» ${ }^{2}$, padre de la negra Noche y de Érebo o «tinieblas» en cuyo vacío la oscuridad intangible está colmada por lo que primigeniamente alberga.

También los órficos, así como Aristófanes en Las aves, comienzan con un gran apagón sus cosmogonías. Desde las sombras a la oscuridad más concentrada hay una potencia que crea y esconde ${ }^{3}$ la multitud de la posibilidad de los deseos.

El autor de Trabajos y días inicia los partos de las generaciones de dioses sembrando la Noche para que de ella, por amores con Érebo ${ }^{4}$, surjan Éter y Hémera. El primero es el cielo superior y el aire claro, antítesis de su padre, la segunda o el Día antítesis de su madre. Familia de singular relación por la generación de contrarios en cuyas presencias está ya la ausencia. A la noche le falta el día y va hacia él, el día anuncia a cada instante que llega la noche. Una progresión que armoniza el contrasentido en lo que parece confrontado. Esa generación mítica comprende una expresión del caos, el juego de escondites que se traduce en nombres y significados.

El mito se proyecta primero de manera simbólica sobre el caos y «sobre esa primera red de inteligibilidad se añaden la filosofía, el arte y las ciencias. En terminología lacaniana se da una oposición entre lo simbólico y lo real, siendo la realidad en la que habitamos lo que del real puede ser simbolizado y lo real aquello que resiste a la inteligibilidad simbólica" ${ }^{5}$. Lo que del caos se deviene realidad, pasa por el alcance simbólico del mito que se da como comprensión primera; poética, filosófica y científica sin que el conocimiento priorice orden o separación entre ellas.

Al pie del divino Helicón, las musas Olímpicas ofrecen al pastor el canto de un «mundo imaginario» ${ }^{6}$ hecho de versos y música.

Pastores rústicos, oprobiosos seres, sólo estómagos, sabemos decir muchas mentiras semejantes a verdades, pero sabemos, cuando lo deseamos, cantar verdades.

La verdad es un saber que se da por deseo de lo contrario hay mentiras que la suplantan asemejándose a ella. Esas «mentiras sinceras» ${ }^{7}$ a las que se refiere el canto contienen ya los inicios de la ficción, en ellas se da el relato, y la verdad que en él se encuentra es una forma de dar a lo real simbolización. Saben y pueden las musas cantar la verdad con tal de desear hacerlo. El narrador nos conecta con su mundo 2011, p. 97.

${ }^{1}$ Hesíodo, Teogonía. Trabajos y días. Presentado por Tariq Ali, Alianza Editorial, Madrid,

${ }^{2}$ Hesíodo, ibidem, p. 25.

${ }^{3}$ John Berger habla en Esa Belleza del deseo como un intercambio de escondites, «El deseo es un intercambio de escondites (hablar de "volver al útero" es una vulgar simplificación)", $c f$. J. Berger, M. Trivier, Esa Belleza, Bartleby, Madrid, 2005, p. 46 y ss.

${ }^{4}$ Hesíodo, op. cit.

5 Francisco José Martínez, «Chaos, Difference, Ritornelo», Jornadas G. Deleuze y Guattari: Refrains of Freedom, Phanteon University, Atenas, 24 a 26 abril de 2015.

${ }^{6}$ Irene Vallejo, El infinito en un junco, Ed. Siruela, Madrid, 2020, p. 121.

7 I. Vallejo, ibidem, p. 122. 
interior en el que apacienta palabras. Desea cuidarlas y con ella cuida su ser mismo en la constante creación de realidad. Lo que da generosamente es la escritura y en ese acto comparte lo que la literatura expresa, es su entrega. Aquí lenguaje y deseo no se distinguen, ambos indiscernibles en un texto literario ${ }^{8}$.

Las hijas de Zeus dan canto al caos como origen y desde el mito nos llega ahora la frescura de lo que se inicia en ese canto. Para Anne Carson, «todo mito es un patrón ornamental,/ una proposición de dos caras/que permite al usuario decir una cosa y significar otra, llevar/[una doble vida./ De ahí la noción primitiva en el pensamiento clásico de que/[todos los poetas mienten./ Y de las verdaderas mentiras de la poesía/ se filtró una pregunta./ ¿Qué une realmente a las palabras con las cosas?»?.

Lo que las Musas cantan es una mentira semejante a la verdad, un escondite de la verdad, juego de escondites decíamos al referirnos al deseo. ¿Qué une realmente al deseo con la verdad?

De las verdaderas mentiras que cuenta el mito sabemos que la verdad se dice por el deseo. Del mito se filtra una posibilidad de respuesta. John Berger escribe que para «la mirada de una tercera persona, el deseo es un breve paréntesis. Desde dentro, una inmanencia y una entrada en la plenitud. Normalmente la plenitud se considera una acumulación. El deseo revela que es un despojamiento: la plenitud de un silencio, de una oscuridad $»^{10}$. Desde esa perspectiva el caos o vértigo tanto como la ficción del vértigo, y así, la verdad o su semejanza, revelan un despojamiento, lo que falta, plenitud de oscuro silencio inicia el relato de Hesíodo, el inicio del derrumbe para que todo nazca.

Con la visión de sombras ${ }^{11}$ se inicia la vida humana, que nace en absoluta dependencia y fragilidad. «El cuerpo humano realiza proezas, posee gracia, picardía, dignidad y otras muchas capacidades, pero también resulta intrínsecamente trágico como no lo es ningún cuerpo de animal (ningún animal está desnudo) ${ }^{12}$. La protección que necesita el cuerpo es por lo mismo la que necesita la mente, no se entiende un ataque selectivo que separe los daños en ambos. Percibir el peligro está en el roce del aire tanto como en un miedo sin función defensiva. Epicuro «intuyó que había que intensificar las relaciones con nosotros mismos antes de pensar en organizarnos como sociedad. Las grandes teorías de sus predecesores habían olvidado un principio esencial de toda felicidad y, por supuesto de toda sabiduría: el

${ }^{8}$ John Freccedo citado por Harold Bloom en Poemas y poetas. El canon de la poesía. Editorial Páginas de Espuma, Madrid, 2015, p. 15.

9 «Pero para honrar la verdad que es suavemente divina y vive entre los dioses debemos (con Platón) danzar en la mentira que vive ahí abajo entre la masa de hombres trágicos y brutos», cf. Anne Carson, La belleza del marido. Un ensayo narrativo en 29 tangos. Editorial Lumen. Trad. Andreu Jaume, Barcelona, 2019, p. 57.

${ }^{10}$ John Berger, $o p$. cit.

${ }_{11}$ Tanizaki en su Elogio de la sombra muestra con extraordinaria sensibilidad lo que muestra la luz de las sombras.

${ }^{12}$ Berger, John. M. Trivier, op. cit. 
cuerpo humano y la mente que lo habita $»^{13}$. El cuerpo humano es el núcleo, dependiente de protección, de la razón y de los sentimientos que busca resguardo por instinto y más allá de ello por la prudencia que le señala la necesidad del resguardo. A cubierto de sentidos y contrasentidos.

Con El Infinito en un junco Irene Vallejo entrelaza las infancias de dos niños pastores, Hesíodo y Miguel Hernández, que maduran en el amor a las palabras como poetas. Saben del poder de la palabra y la defienden como si en su cuidado se diera el significado. La autora identifica en Hesíodo el «comienzo de la genealogía de una poesía social» ${ }^{14}$, algo que al margen de esa genealogía y los siglos de diferencia comparte con la poesía de Miguel Hernández.

Hesíodo escríbe críticamente contra los reyes y las condiciones de vida, con versos tan ácidos que tal vez por ello han pervivido.

Tomamos un fragmento de su obra Trabajos y días en cuyo título ya se da un alegato:

Si te coge el deseo de la fatigosa navegación: cuando las Pléyades huyendo de la vigorosa fuerza de Orión caigan sobre el brumoso Ponto, entonces soplos de toda clase de vientos se lanzan impetuosamente; recordándolo entonces ya no debes tener las naves en el vinoso Ponto, sino trabajar la tierra como te aconsejo: vara la nave en tierra firme y fíjala con piedras por todas partes, para que haga frente a la fuerza de los vientos que soplan húmedamente, quitándole el tapón para que no la pudra la lluvia de Zeus. Las jarcias bien dispuestas todas colócalas en tu casa, en orden, plegando las alas de la nave surcadora del mar. Cuelga el bien trabajado gobernalle sobre el humo.

Tú mismo espera hasta que llegue la estación de la navegación. Entonces saca al mar el ligero navío y equípalo disponiendo la carga para llevar ganancia a casa. Como mi padre y el tuyo, gran insensato Peres, se hacía a la mar en las naves, por estar necesitado de buen sustento, el que en otro tiempo llegó aquí surcando el amplio Ponto, abandonando en negra nave a Cisme Eolia, no escapando a abundancia, riqueza y felicidad, sino a la malvada pobreza que Zeus da a los hombres y vivió cerca de Helicón, en Ascra, penosa aldea, mala en invierno, terrible en verano, y nunca buena ${ }^{15}$.

¿Cuándo hacerse a la mar? Lo tomamos como una señal de prudencia. La prudencia en la denuncia, a pesar del deseo de navegar, de luchar contra la pobreza, aconseja amarrar el navío y trabajar la tierra, parar y hacer de la cautela rasero con el riesgo ${ }^{16}$.

${ }^{13}$ Emilio Lledó, Fidelidad a Grecia. «Lo bello es difícil» y otras ideas que nos enseñaron los griegos. Ed. Taurus, Madrid, 2020, p. 43.

${ }^{14}$ I. Vallejo, op. cit., p. 123.

${ }^{15}$ Hesíodo, op. cit., p. 82.

16 Es destacable en ese sentido la filosofía de Spinoza, el cual, bajo el lema Caute, muestra la prudencia a la que nos referimos. No podía ser menos que cauteloso quien pretendía dar ascuas a significados fríos de vida. El spinozismo contenía palabras encendidas contra una vida servil. Un pensar así siempre está señalado para ser destruido, no importa el punto de la historia en el que ocurra. 
Miguel Hernández murió en la cárcel dejando a su poesía protegida contra la fuerza del olvido. Su elección era como dijimos cuidar la palabra y con ella buscar un cobijo de significados para sí mismo y para quien lo lee. Guardó su vida de la condición de siervo como acaso sí lo son quienes encarnan sus versos:

Cuerpos que nacen vencidos,/vencidos y grises mueren:/vienen con la edad de un siglo,/y son viejos cuando vienen.

Con una memorable alocución despachó Prometeo a Hermes, mensajero de los dioses: «Mi desgracia, sábelo con claridad, yo no la cambiaría por tu condición de siervo... Es mejor, creo, ser esclavo de esta roca que ser fiel mensajero del padre Zeus $»^{17}$. El poeta muestra la misma fuerza prometeica que el propio Marx utiliza para revelar su filosofía: «Lo que era luz interior se convierte en un fuego devastador hacia el exterior ${ }^{18}$. El resguardo que ofrece la cautela se mide al riesgo por deseo de verdad. Al hilo del mito aquello que el cuerpo guarda, cuando toca trabajar la tierra, es su habla y con ella el caos real; sin embargo, cuando llega la estación de navegación lo que al cuerpo cubre es la realidad del caos y por ello el habla.

Lo que perdura del texto guarda la voz como un ungüento se guarda en la vitrina de una botica. A través del alfabeto la voz cura de las picaduras de la desmemoria y es ahí donde los libros nos dejan a resguardo, bajo la sombra de los árboles de quienes son hijos, árboles que «fueron el primer hogar de nuestra especie y, tal vez, el más antiguo recipiente de nuestras palabras escritas» ${ }^{19}$.

Las bibliotecas hechas de hojas se levantan como árboles hechos de páginas en los que se está a salvo de una especie de falta constituida por la propia vulnerabilidad. La cobertura de los libros ofrece un saber de apariencia incontestable, e incluso tiernamente intimidatoria, si a la razón se le une la emoción donde el vocabulario aumenta la vida.

Ese saber de la falta convierte al deseo en potencia para cualquier cultura. Por ejemplo, en la cultura maorí cuyas famosas danzas consiguen expresar intimidación guerrera pero también, a través de sus Haka, hablan de lo que desean como práctica que hace realidad en bienvenidas, despedidas, competencia, aniversarios, respeto o agasajo. Aquí se repite la mentira verdadera en la danza que, como en el

Amenaza su contagio, como podemos leer en esta denuncia al santo oficio cursada por Niels Stensen en el año 1677: «Ya otros habrán informado al Santo Oficio sobre el mal que la nueva filosofía ha generado en Holanda a través de un tal Spinosa; no obstante, la gravedad del mal y el peligro de su propagación son de tal envergadura que no se puede tener por demasiada toda la solicitud que se emplee en descubrirlos más y más, y en buscar los remedios oportunos tanto para preservar a otros de su infección cuanto a fin de curar a aquellos que hayan sido envenenados, si es posible» (Baruj Spinoza. Ética demostrada según el orden geométrico. Ed. Trotta. Edición Pedro Lomba, Madrid, 2020, cf. Anexo I: «Denuncia de Niels Stensen de la filosofía de Spinoza al Santo Oficio», p. 429).

${ }_{17}$ Prólogo de Tariq Ali para Teogonía. Trabajos y días, de Hesíodo, op. cit., p. 82.

${ }^{18}$ Hesíodo, ibidem, p. 82.

19 I. Vallejo, op. cit., p. 276. 
texto, se transforma en lo que de verdad se llega a sentir: sus movimientos son lenguaje que cubre falta y vulnerabilidad.

La calidez de las letras escritas ofrecen un lugar seguro. Escribir nos obliga a pertenecer a una guarida literaria y caótica de la que surja la escritura. Pero no solo escribir sino dibujar forma parte imaginaria de esa guarida. Si con esa idea pretendemos delinear los bordes del cuerpo debemos señalar punzante en su centro la imposibilidad de olvidarnos de su constante grabado. Las heridas en él cicatrizan como en los árboles cicatrizan los nombres escritos en sus cortezas. Eso se presenta como prueba de vida, es decir, «si hubiera alguien sin heridas en este mundo, viviría sin deseo ${ }^{20}$, algo incompatible con ser. Hay grabada una historia en la piel, en parte tatuada a nuestra voluntad y en parte porque lo imprevisible se hace visible en ella. Lo que queda manifiesto es la fragilidad del límite, allí donde el cuerpo necesita estar en el mismo nivel de protección que su mente, llevando a la conciencia el instinto de supervivencia. Llevar a favor la energía del caos, como principio subyacente $^{21}$, en movimiento vital donde aparece la comprensión y la comunicación como en el origen, es decir, lo "primero fue el habla. Una necesidad de sentir la compañía de los otros, de arrancarse de la originaria soledad, de emitir sonidos que la lengua fue articulando, modulando, convirtiendo en palabras $\aleph^{22}$. En esa necesidad se plantea el origen. En el principio fue el caos ruido, el ruido de fondo $o^{23}$ pero también en el principio la palabra. ¿Cómo si no por ella sabemos del Caos?24.

En latín liber significaba 'libro', la misma palabra que originariamente se refería a la "película fibrosa que separa la corteza de la madera del tronco»" ${ }^{25}$ Los libros se reproducían a mano antes de la imprenta. De la fortaleza física de las páginas dependía la vida de este o aquel pensamiento. La copia a mano sobre un soporte no menos débil que ella nos ha dejado un ejemplo resistencia. La historia, los cálculos, los poemas, todo hallazgo que pudiera ser escrito era cuerpo de libro. Cuerpo a cuerpo en «una batalla contra el tiempo para mejorar los aspectos tangibles y prácticos -la duración, el precio, la resistencia, la ligereza- del soporte físico de los textos ${ }^{26}$.

Hoy hemos pasado a un mundo de imágenes donde las palabras se plasman en otros soportes, un «universo abstracto en el que estamos y que acaba siendo

${ }^{20}$ J. Berger, John. M. Trivier, op. cit, p. 46.

21 «El caos no solo es inicio (temporal) sino principio (esencial). Mientras que el inicio desaparece, el principio permanece subyacente en el proceso de desarrollo", $c f$. F.J. Martínez, "Chaos, Difference, Ritornelo", op. cit.

${ }^{22}$ E. Lledó, op. cit., p.19.

${ }^{23}$ Este texto es una traducción del Prefacio escrito por Michel Serres en su libro Hèrmes IV. La distribution, Minuit, 1977, pp. 9-14. (Las cursivas son mías).

${ }^{24} \mathrm{El}$ ser humano y en general los seres vivos convierten ese caos informe e indefinido en un cosmos introduciendo orden. Pero este proceso de cosmogénesis, es decir, de generación del orden, nunca es definitivo, por eso a lo que nos enfrentamos siempre es a un Caosmos: un cosmos que "conserva el caos en su seno", $c f$. F.J. Martínez, op. cit.

25 I. Vallejo, op. cit., p. 276.

${ }_{26}$ Ibidem, p. 76. 
el universo que somos $\star^{27}$. Puede ser este, apunta Lledó, una expresión que señala el territorio de la intimidad: microcosmos expandido por la comunicación con lejanos corresponsales. Para ellos la respuesta parte de considerarnos palabra que interroga y no silencio de soledad egoísta, dice el filósofo. «En el diálogo que cada uno lleva con su intimidad, tenemos que ser capaces de sentir [...] que esas palabras lo son de verdad cuando son palabra compartida ${ }^{28}$.

Es usual que en los viajes largos e incómodos las niñas y los niños insistan en la pregunta ¿̇cuánto falta? Una pregunta que en su apariencia es banal y que, sin embargo, en relación con el día a día, contiene la fuerza del presente, la carga de vida que se traduce en hábito o novedad en él. Entretener ahora significa, en abrumadora proporción, colocar una pantalla delante de la vista. Así funciona para los adultos, y, lo que es más inquietante, para los niños y las niñas. Ese gesto actúa en sus efectos como la causa llamada 'efecto mariposa'. No ver el paisaje que pasa por la ventana porque la vista está en una pantalla es ya de hecho el primer efecto causado por el movimiento de las alas de la mariposa. Ni árboles, ni océanos, ni pájaros a los que no se les pueda repetir el movimiento a golpe de pulsador. Esa ausencia de aire libre indica cuán asfixiante es el interior de la burbuja ${ }^{29}$ virtual. Ya no es el microcosmos deseable sino el aislamiento y la pérdida. Paradójicamente esa misma burbuja hace las veces de lugar seguro, Lledó bautiza el término "aterrorismar»" para indicar que esto se produce por el miedo y una culpabilidad universalizada. En este caso el peligro no es salir a la mar, al vinoso Ponto del que habla Heráclito, porque aquí estamos ante un gran naufragio aunque ciertamente no se naufrague todos los días, solo ocurre «donde el navío pasa en medio de voces insensatas» ${ }^{31}$.

Nuestro hábitat representa una burbuja de vida en la que se engloba todo lo que guarda relación con el planeta, no podemos saber si estas mismas o simila-

27 E. Lledó, op. cit., p. 187.

28 Ibidem, p. 191.

29 «En su formulación original, la teoría de la burbuja apareció por primera vez en un libro de Eli Pariser, El filtro burbuja: cómo la web decide lo que leemos y lo que pensamos, publicado en el 2011. Desde que o afín a nuestro mundo cultural o ideológico (nuestra burbuja). Sirviéndose de datos procedentes de nuestras búsquedas anteriores, nuestros contactos, las páginas que hemos visitado, etc., las inteligencias artificiales que administran solamente lo que creen que puede gustarnos o interesarnos, aislándonos a efectos prácticos de ideas nuevas o alejadas de nuestra percepción de la realidad [...]. Al vivir en nuestra burbuja, creemos que lo que percibimos como normal y compartido representa toda la realidad. Y entonces llega Trump para hacernos ver que no es así», $c f$. Stefano Mancuso, La nación de las plantas, Ed. Galaxia Gutenberg, Barcelona, 2020, p. 25.

30 «Hay medidas más o menos justificadas que nos hacen creer que nuestro vuelo, o nuestro acceso a un determinado edificio, es más seguro; y con la esperanza de esa seguridad aceptamos tales controles y acabamos incorporándolos como hábitos necesarios de nuestro comportamiento social, como accidentes inevitables de nuestra existencia. Es cierto que en un mundo aterrorizado hemos llegado a asumir que no hay otro remedio que aproximarse a la presunción de culpabilidad de todo ser humano y a que, por unos momentos, tengamos que soportar la inclusión en una etérea lista de malhechores», $c f$. E. Lledó, op. cit, p. 206.

${ }^{31}$ Este texto es una traducción del Prefacio escrito por Michel Serres en su libro Hèrmes IV. La distribution, Minuit, 1977, pp. 9-14. 
res relaciones se dan en otros planetas. Si al igual que en la Tierra hay en el universo otras burbujas de vida con sus variedades y relaciones particulares. Pensar en esas burbujas como condición universal no es un planteamiento seguro, porque en realidad cabe la posibilidad de que seamos la única burbuja. Hay que insistir: no lo sabemos, pero de hecho podemos ser los beneficiarios y beneficiarias de «un inconmensurable golpe de suerte ${ }^{32}$ que, por así decirlo, hay que mantener.

Es responsabilidad humana esa gestión. Y cae normalmente en manos de pocas personas tal dominio, lo que hace de este asunto algo más agudo, pues la responsabilidad compartida, además de la voluntad individual, depende de un acuerdo político cuyo interés sea claramente asumir el cuidado de la biodiversidad del planeta.

¿Qué nos da como especie ese privilegio? Mancuso recurre a los conceptos de democracia y aristocracia para pensarlo. En el primer caso o vía democrática; la idea de por qué enseñoreamos la tierra se atribuye a una cuestión numérica, es decir, el número de individuos marca democráticamente el gobierno. Sin embargo, no se sostiene, así pues la especie humana constituye la diezmilésima parte de la biomasa del planeta. Son las plantas las que ocupan el ochenta por ciento y su relevancia es fundamental para la vida. De hecho, si ellas tuvieran la posibilidad de gobernar el planeta la cooperación sería toda la norma. En el segundo caso o vía aristocrática: parte de un don por nacimiento que nos diera ese privilegio convirtiéndonos en la especie elegida (aristos, 'mejor' y cratos 'poder') del planeta, un derecho casi divino que de suyo ya es poco razonable. Sin embargo, se sostiene de una u otra forma que somos mejores que el resto de seres vivos porque «nuestro gran cerebro nos permite hacer cosas que a otras especies les resultan imposibles [...]. Pero en la historia de la vida, ¿qué significa "mejor"?»33. No parece un concepto valioso, puesto que en dicha historia no hay un fin por metas. Lo único que resulta óptimo para cada ser vivo es sobrevivir; un objetivo más claro y unánime, incluso es el más exigente con el cuidado de la casa. Contra todo pronóstico nuestro «formidable cerebro ha creado peligros que en cualquier momento podrían barrernos de la faz de la tierra ${ }^{34}$, ese mismo cerebro capaz de crear desde el caos hasta el habla de los árboles pertenece a una especie que en condiciones normales podría tener una supervivencia de unos 4700000 años y que sin embargo cuenta aproximadamente con 100000 años más de existencia después de los desastres producidos.

Desde el cosmos como «resultado de proyectar redes de inteligibilidad sobre el caos primordial ${ }^{35}$ hasta el entramado reticular conformando la energía de la cooperación, hay un intento de construcción cuya simbolización explique el «absolutismo de lo real que se yergue amenazador ${ }^{36}$. Ese intento de buscar resguardo nos ha llevado a través de los árboles hasta las hojas de los libros. Una manera de proteger el cuerpo protegiendo lo que constituye la materia de la mente. En ningún caso

32 Stefano Mancuso, op. cit., p. 26.

33 Ibidem, p. 29 y ss.

${ }^{34}$ Ibidem, p. 31 y ss.

35 Cf. F.J. Martínez, op. cit.

36 Ibidem, op. cit. 
nuestro cuerpo se puede resguardar al margen de la naturaleza. Somos naturaleza y debemos extender un acuerdo social ${ }^{37}$ hacia el resto de la naturaleza, un acuerdo al que invita Mancuso en La nación de las plantas. «La Tierra es la casa común de la vida ${ }^{38}$. La misma de ancho pecho, en palabras de Hesíodo «sede siempre firme de todos los inmortales que ocupan la cima del nevado Olimpo; [en lo más profundo de la tierra de amplios caminos, el sombrío Tártaro]»"39, Gea es compleja por la vida que alberga, frágil belleza que depende del oxígeno que proviene de la fotosíntesis. Bajo el habla de los árboles en esa «nación de plantas» de la que nos habla Mancuso, «llamar a nuestro planeta Gaia y considerarlo un único ser vivo» ${ }^{40}$ surge de la importante función de la vida en el planeta. M. Serres, en similar sentido propone un contrato con la naturaleza con derechos que hay que establecer y respetar. Se trata de recibir a cambio la posibilidad de la supervivencia de la especie humana, única especie que destruye su propia casa ${ }^{41}$. El filósofo francés advierte que «a veces ocurre que lo que contribuye a liberación se invierte y deviene un poder que nos esclaviza nos quedamos con la desconcertante impresión de que nada hay nuevo bajo el sol» ${ }^{42}$. Pintada, no vacía:/pintada está mi casaldel color de las grandes/pasiones y desgracias, recita en "Canción última» Miguel Hernández.

Pertenece a la materia del cuerpo albergado, el deseo de residir o donde resistir la acción de la intemperie mientras se dirige al futuro imposible. Lo que el habla alcanza es el caos de esa imposibilidad; la causa en el origen y el efecto regresando a ella, la amplitud de efectos, el efecto indeseado, las causas inadvertidas. Lo imprevisible. En ese principio siempre caótico y generador, hay imágenes y melodías a las que acudimos desde el inicio del lenguaje porque tienen la potencia de hacernos sentir a cubierto. Llegar a través del espacio que ocupa el sonido escrito en el interior de los árboles, allí donde encontró el lenguaje su casa, a una morada de savia donde

${ }^{37}$ En relación con este tema sobre la necesidad de cuidar la casa común de la vida, Michel Serres en El contrato natural defiende con nitidez la necesidad de acabar con la violencia sobre la naturaleza. En El contrato natural, Serres clama por la urgencia de establecer un pacto con el mundo natural, con el que hemos llegado a establecer una relación de dominio posesivo y de violencia. En dicho pacto serían partes contractuales, por un lado, la comunidad humana asociada por lo que Rousseau llamó el Contrato social y, por otra, la naturaleza global, el planeta Tierra. No es suficiente con tener un contrato social de buena convivencia, también es necesario un contrato natural que comprometa a todos los seres humanos con la defensa de los ecosistemas y la sostenibilidad de los demás bienes naturales (mal llamados recursos naturales) https://www.elmundo.com/noticia/Michel-Serres-y-el-contrato-natural/376813.

38 Stefano Mancuso, op. cit., p. 17.

${ }^{39}$ Hesíodo, op. cit., p. 25.

${ }^{40}$ Stefano Mancuso, op. cit., p. 24.

41 «Es por eso que la Nación de las Plantas, nacida cientos de millones antes que ninguna nación humana garantiza la soberanía sobre la Tierra a todos los seres vivos: para evitar que una sola especie presuntuosa pueda extinguirse antes de tiempo, demostrando con ello que su enorme cerebro no era ni mucho menos una ventaja, sino una desventaja evolutiva", $c f$. Stefano Mancuso, ibidem, p. 31.

${ }^{42}$ https://laquimera.typepad.com/laquimera/2017/06/diario-de-lecturas-el-contrato-natural-de-michel-serres.html. 
los significados son resguardo del cuerpo, es la potencia de la vida: práctica de riesgo y deseo desde la fragilidad tomando la realidad de esa existencia a partir del caos. «Una casa nos detuvo/parecía un Túmulo-/el Tejado a penas visible-/la Cornisa-en el Suelo» ${ }^{43}$.

Recibido: 1 de junio de 2020; ACEPTAdo: 26 de junio de 2020

43 Emily Dickinson, Carta al mundo y otros poemas. Ed. Libros del zorro rojo, traducción María Negroni, Barcelona-Buenos Aires-Ciudad de México, 2019, sin número. 